\title{
HOMENS TRANS E ATIVIDADE FÍSICA: A CONSTRUÇÃO DO CORPO MASCULINO
}

\author{
TRANSSEXUAL MEN AND PHYSICAL ACTIVITIES: THE CONSTRUCTION OF \\ THE MALE BODY
}

HOMBRES TRANS Y ACTIVIDAD FÍSICA: LA CONSTRUCCIÓN DEL CUERPO MASCULINO

\author{
Jéssica Leite Serrano*, Iraquitan de Oliveira Caminha*, Isabelle Sena Gomes*
}

Palavras chave:

Pessoas

transgênero.

Exercício físico.

Corpo

Keywords:

Transgender

persons.

Physical Exercise.

Body.

\begin{abstract}
Resumo: Considerando a possibilidade da participação das atividades físicas na construção de características físicas como força e rigidez muscular por homens trans, este estudo buscou analisar a relação dos homens trans com as atividades físicas no processo de "masculinização". Participaram do estudo oito homens trans que fazem uso dos serviços oferecidos pelo Ambulatório de Saúde integral para Travestis e Transexuais na cidade de João Pessoa/PB, que foram submetidos a uma entrevista semiestruturada e um questionário socioeconômico, analisados com base na proposta de Bicudo para a análise fenomenológica. Este estudo concluiu que os entrevistados fazem uso das atividades físicas em busca do ganho de massa corporal e definição muscular, aspectos que na visão deles remetem a um corpo masculino, reforçando não apenas a sua masculinidade, mas ajudando na construção da sua identidade sexual.
\end{abstract}

Abstract: Considering the possibility of participating in physical activities to build physical characteristics such as strength and muscular rigidity by transsexual men, this study analyzed the latter's relationship with physical activities in the process of "masculinization". Subjects were eight transsexual male users of the services provided by the Total Health Care Ambulatory for Transvestites and Transsexuals in the city of João Pessoa, Paraíba. They answered socioeconomic questionnaires and semi-structured interviews, later submitted to Bicudo's Phenomenological analysis proposal. This study concluded that respondents used physical activities to increase body mass and muscle definition aspects that, in their views, refer to a masculine body, not only reinforcing their masculinity but also helping them to build their sexual identity.

Palabras clave: Personas transgénero. Ejercicio Físico. Cuerpo.
Resumen: Considerando la posibilidad de la participación de las actividades físicas en la construcción de características físicas como fuerza y rigidez muscular por hombres trans, este estudio analizó la relación de los hombres trans con actividades físicas en el proceso de "masculinización". Participaron ocho hombres que hacen uso de los servicios ofrecidos por el Ambulatorio de Salud Integral para Travestis y Transexuales en João Pessoa, Paraíba, que fueron sometidos a una entrevista semiestructurada y a un cuestionario socioeconómico, analizados con base en la propuesta de Bicudo para el análisis fenomenológico. Este estudio concluyó que los entrevistados hacen uso de las actividades físicas buscando ganar masa corporal y definición muscular, aspectos que en su visión remiten a un cuerpo masculino, reforzando no solo su masculinidad, sino ayudando en la construcción de su identidad sexual.
*Universidade Federal da Paraíba. João Pessoa, PB, Brasil. E-mail: jessica_jp4@ hotmail.com; caminhairaquitan@gmail.com; euisabelle@yahoo.com.br

Recebido em: 01-06-2018 Aprovado em: 11-12-2018 Publicado em: 18-03-2019

DOI: https://doi.org/10.22456/1982-8918.83494 (c) (i) () Licence 


\section{INTRODUÇÃO}

A pessoa transexual pode ser compreendida como uma pessoa que se sente "[...] insatisfeita com algumas das suas condicionantes biológicas e busca alternativas para manter em equilíbrio o que deseja ser e o que é" (SERRANO; CAMINHA; GOMES, 2017, p. 1120). A temática da transexualidade começou a ser discutida na década de 1960, quando os estudos de gênero se tornaram mais evidentes e consistentes fora do país (BENTO, 2014b). Os debates sobre gênero ampliaram-se no Brasil a partir dos anos 1970, junto com os movimentos feministas pró-democracia e igualdade, em um contexto de ditadura militar, mesmo período em que a ONU prevê o início da Década da Mulher. Este cenário impulsionou uma onda de estudos de gênero que refletiu também na temática da transexualidade.

Testemunhamos atualmente o crescimento da produção de artigos e livros que falam sobre transexualidade. Na plataforma SCIELO, por exemplo, os artigos disponíveis ${ }^{1}$ datam de 1963 (um artigo) até os dias atuais, sendo que no ano 2000 foram 39 publicados e em 2017 foram 235 (um aumento de mais de 500\% na produção). Entretanto, esse crescimento é desigual se observarmos estudos sobre a transexualidade masculina de maneira particular, considerando que pouco se discute sobre ela, expressando um protagonismo da transexualidade feminina nos saberes produzidos (ÁVILA; GROSSI, 2010; LIMA, 2014).

Embora o número de estudos seja crescente, ainda há várias convergências e divergências sobre a temática da transexualidade. É recente (2016), por exemplo, a publicação de um estudo realizado pela revista médica britânica The Lancet Psychiatry² em diversos países, que aponta que transexualidade não é um distúrbio psiquiátrico, enquanto isso, alguns autores como Berenice Bento (2014a), Guacira Louro (1997) e Judith Butler (2003) já discutem esta questão tratando a ideia de gênero como algo performativo e cultural.

Para Almeida (2012) os homens trans ${ }^{3}$, especificamente, são um grupo de pessoas que têm se tornado mais visíveis no cenário público. Embora ainda haja muito por fazer, eles conquistaram nos últimos anos direitos e espaço nos serviços oferecidos pelo SUS (Sistema Único de Saúde), cujo dever é garantir suporte no processo transexualizador e disponibilizar o tratamento hormonal mediante acompanhamento profissional. Contudo, Rocon et al. (2018, p.51) apontam dificuldades relatadas pelos homens transexuais na busca por atendimento e pela neofaloplastia, o que para os sujeitos representa "[...] desigualdade na produção de tecnologias para intervenção nos corpos de homens trans". O tratamento hormonal oferecido pela rede pública de saúde - associado a cirurgias e outros recursos - viabiliza certas modificações corporais, mas há questões de ordem jurídica que oferecem suporte para o reconhecimento dos trans como homens na esfera do direito civil.

Por decisão dos Supremos Tribunais (Eleitoral e Federal), assim como para as mulheres trans, tal reconhecimento já pode ser obtido no Brasil sem a necessidade de cirurgia

1 Artigos em português, inglês e espanhol, que surgem na plataforma a partir dos descritores: "trans", "transexual" e "transexualidade". 0 termo/descritor "trans", embora pareça coloquial, foi categoria nativa bastante utilizada como forma de autodenominação pelos entrevistados da pesquisa da qual este artigo faz parte.

2 Pesquisa inicial de várias a serem realizadas no Brasil, França, Índia, Líbano e África do Sul. Este estudo acredita que pesquisas recentes como esta contribuíram com a elaboração da $11^{\circ}$ versão do CID (Classificação Internacional de Doenças/OMS), apresentada em maio de 2018 (Genebra), culminando na retirada da transexualidade da categoria de doença mental.

3 Para fins deste estudo, dentre outros possíveis, será adotado o termo "homem trans" (categoria nativa) como a pessoa que nasceu biologicamente mulher, mas se identifica com o gênero masculino, e, portanto, como homem. Sendo assim, entre outras formas de classificação presentes na literatura, tais como: "trans homens, homens transexuais, homens transgêneros e FTM (female-to-male), podendo ainda existir outras possibilidades de reconhecimento não catalogadas" (SOUSA; IRIART, 2018); optamos por "homens trans" seguindo a fala dos nossos colaboradores. 
ou tratamento hormonal, uma vez que está garantido constitucionalmente o direito à substituição de prenome e sexo no registro civil por via administrativa ${ }^{4}$. Porém, a questão do reconhecimento enquanto homem ou mulher trans vai além do domínio administrativo e dos direitos civis, tocando também a questão do corpo masculino e feminino enquanto parte da construção da identidade do sujeito.

O corpo tem relação direta com o reconhecimento social, é parte do que o sujeito é e de como ele percebe sua relação com o mundo. "A vida de mulheres e homens trans - transexuais, travestis e transgêneros - parece apresentar a transformação do corpo como crucial na sua produção, que pode ser realizada por meio de diversos recursos" (ROCON et al., 2018, p.44). Isso por que o corpo carrega símbolos baseados na cultura que expressam características de gênero com as quais o sujeito se identifica, já que ele é um constructo ao alcance da visão do outro, que tanto comunica especificidades do homem e da mulher quanto revoluciona esses estereótipos (LE BRETON, 2013).

Ao mudar o corpo, a pessoa pode optar por um novo modelo que a caracterize como ela se identifica (MALYSSE, 2002). Para tal empreendimento, surgem como opção os recursos/ saberes contemporâneos oferecidos pela Biomedicina. Entre estes recursos, este estudo se detém a aprofundar a relação dos homens trans com a atividade física, considerando atividade física como a realização de movimentos corporais que mobilizam um gasto energético acima do repouso (CARVALHO, 2006).

O leque de atividades físicas envolve jogos, lutas, danças, esportes, exercícios físicos, atividades laborais e deslocamentos (PITANGA, 2002). Nos últimos anos, também por influência da mídia, que desde os anos 1980 difunde em seus diversos veículos de comunicação corpos perfeitos modelados à base de exercícios vigorosos, nota-se um aumento significativo no número de pessoas que procuram atividades físicas (TAHARA; SCHWARTZ; SILVA, 2003), principalmente nas academias de ginástica, e os homens trans não estão imunes - nem presos - a esta tendência. Textos como o de Berenice Bento (2012) e Rego (2014) inspiraram esta hipótese com os relatos de homens trans que realizaram mudanças corporais através de "exercícios vigorosos" na direção de um corpo que expressasse sua identidade de gênero.

As palavras mudança e transformação são presentes na vida dos sujeitos trans. Sousa e lriart (2018, p.5) reconhecem que as "modificações corporais são procedimentos nos quais os homens trans visam a alcançar o corpo idealizado, muitas vezes, relacionado a um padrão de corpo cisgênero masculino". Diversas fontes jornalísticas falam, inclusive, em renascimento 5 . Com exceção daqueles que mesmo se identificando como transexuais decidem "contornar" a insatisfação com condicionantes biológicas e permanecer recônditos, ser homem ou mulher trans, por si, na maioria dos casos demanda trans-formação.

Trans-formação neste caso quer dizer mudar de forma, assumir características corporais que não condizem com a identidade cisgênero, mas não necessariamente seguir um padrão de masculino.

Os homens trans constroem arranjos entre sexo e gênero que ultrapassam a linearidade do padrão cisnormativo e ratificam outras possibilidades de conceber a constituição humana [...]. Isso não lhe imputa a heteronormatização dos seus desejos" (SOUSA; IRIART, 2018, p.2).

4 De acordo com a decisão de 1 de março de 2018, a alteração nos documentos pode ser feita em cartório, mesmo sem autorização judicial. 5 Ver O papel do SUS em ajudar cidadãos transexuais a renascer (LIMA, 2017). 
A ideia de transformar a si não pretende operar generalizações, mas apontar a possibilidade de (re)construção daquilo que os sujeitos percebem como relação gênero-corpo tendo a atividade física como ferramenta. Sendo assim, compreende-se neste estudo que ser homem trans não implica, mesmo nos casos de busca por aceitação, a reprodução de uma construção social de masculinidade específica, da qual o corpo faz parte e para a qual é importante, mas provoca a reflexão sobre a ampliação no leque de masculinidades possíveis.

Casos conhecidos de atletas como o de Fallon Fox (GRESPAN; GOELLNER, 2014), Tifanny Abreu (primeira atleta trans a atuar na elite do vôlei brasileiro) e dos Meninos Bons de Bola ${ }^{6}$ ganharam visibilidade na mídia trazendo à tona demandas sociais contemporâneas a serem discutidas também pela Educação Física, por sua aproximação com a questão do corpo e do esporte. Isto tornou-se tão evidente que há dois anos o Comitê Olímpico Internacional (COI) modificou a resolução sobre transexuais em competições oficiais, determinando, entre outras coisas, o fim da obrigatoriedade da cirurgia de mudança de sexo e um limite de dez nanomol de testosterona por litro de sangue (doze meses antes da competição), fixado para mulheres trans ${ }^{7}$.

$\mathrm{Na}$ esteira dos limites hormonais é importante citar o caso da atleta de vôlei Érika Coimbra, mulher cisgênero reprovada no "teste de feminilidade" do COI. Érika foi "poupada" de competir (1998-1999) por apresentar uma grande quantidade de testosterona no sangue em decorrência de uma má-formação dos órgãos reprodutores. Seu caso explicita como é complexa a questão do ser homem ou mulher no esporte e que há outras formas não binárias de gênero colocadas em posições diametralmente opostas em algumas situações.

Considerando o que foi dito, este estudo pretende explicitar questões de gênero-corpo que tocam o universo do esporte e do exercício físico, contribuindo assim com a promoção de formas de inclusão das pessoas transexuais em espaços sociais destinados à prática de atividade física. $O$ que se segue é uma discussão sobre a relação entre atividade física, enquanto recurso para operar modificações na construção dos corpos, e a produção das masculinidades por homens transexuais.

\section{PERCURSO METODOLÓGICO}

Esta pesquisa caracteriza-se como qualitativa exploratória e adota uma perspectiva interpretativa fenomenológica, em que são estudados os significados dos fenômenos, fatos, manifestações, vivências, ideias e sentimentos; na crença de que estes podem responder aos objetivos levantados (GASKELL; BAUER, 2012).

Os sujeitos sociais da pesquisa foram oito homens trans que recebiam atendimento no Ambulatório de Saúde Integral para Travestis e Transexuais (Ambulatório TT) localizado no anexo do Hospital Clementino Fraga, na cidade de João Pessoa/PB. Optamos por realizar a pesquisa no ambulatório pela dificuldade de acessar o público transexual em outros espaços.

O Ambulatório TT foi inaugurado em julho de 2013 pelo governo do Estado da Paraíba e hoje é referência nacional para o Ministério da Saúde por congregar diversos serviços. Equipes de diferentes estados frequentam a unidade, que é voltada para 0 atendimento de

6 Equipe de futebol formada por homens trans que ganhou visibilidade na mídia e identifica-se como equipe de arte, ativismo e resistência. 7 Além da possibilidade especulada deste limite reduzir para cinco nanomol/litro de sangue, em abril de 2018 a Folha de S. Paulo publicou um levantamento que afirma que apenas 13 das 33 federações esportivas seguem tais normas (ciclismo, escalada, golfe, halterofilismo, handebol, hóquei na grama, judô, pentatlo moderno, remo, rúgbi, tênis, tiro, tiro com arco) (GHIROTTO, 2018). 
travestis e transexuais que buscam realizar o processo transexualizador, não sendo oferecidos outros serviços de saúde que não estejam ligados a esse processo. 0 ambulatório atende os 223 municípios paraibanos e mais dois estados da Região Nordeste: Pernambuco e Rio Grande do Norte, contando com uma equipe composta por ginecologista, endocrinologista, psiquiatra, fonoaudióloga, nutricionista, assistente social e psicólogo. ${ }^{8}$

O critério de inclusão adotado foi se identificar como homem trans, o critério de exclusão foi deixar de participar de alguma etapa da pesquisa ou não entregar o Termo de Consentimento Livre e Esclarecido assinado.

A fim de levantar elementos de análise para o estudo, o instrumento utilizado foi a entrevista do tipo semiestruturada, que parte de perguntas previamente definidas a partir do objetivo da pesquisa, mas que possibilita a realização de novas perguntas conforme a necessidade surgida em campo (SANCHO GIL, 2010), e um questionário socioeconômico a fim de ter uma visão geral do grupo entrevistado.

Salienta-se que o presente trabalho foi submetido ao Comitê de Ética em Pesquisa (CEP) da Universidade Federal da Paraíba (UFPB), seguindo a Resolução № 466/13 do Conselho Nacional de Saúde, com aprovação em fevereiro de 2016, obtendo assim Registro no CEP/CCS/ UFPB e CAAE de número: 50755715.7.0000.5188. Após a autorização do Comitê de Ética em Pesquisa, demos início à realização das entrevistas e questionários, aplicados nas dependências do ambulatório, de forma individual em uma sala reservada.

Para a análise das falas obtidas, utilizamos a proposta de Bicudo (2011), que busca evidenciar os sentidos, efetuar sínteses de unidades de significado, bem como analisar as falas através de categorias de análise. Sua proposta recomenda quatro passos. 0 primeiro é a leitura atenta das falas obtidas realizando conexões entre as falas e o fenômeno estudado. 0 segundo é evidenciar os sentidos a partir das necessidades da questão estudada. O terceiro é definir as unidades de significado, unindo sentidos colocados em evidência e, por fim, o último passo é estabelecer as redes de significados.

\section{RESULTADOS E DISCUSSÃO}

$\mathrm{Na}$ tentativa de traçar um panorama mais amplo dos colaboradores deste estudo, facilitando assim a compreensão das falas analisadas, o quadro abaixo sintetiza as informações obtidas na aplicação do questionário socioeconômico.

Quadro 1 - Quadro geral dos entrevistados.

\begin{tabular}{|c|c|c|c|c|}
\hline Entrevistados & Idade & Relacionamento & Escolaridade & Profissão \\
\hline E1 & 32 & Casado & Ensino Médio completo & Comerciante \\
\hline E2 & 20 & Solteiro & Ensino Médio incompleto & Estudante \\
\hline E3 & 24 & Solteiro & Ensino Médio completo & Atendente de telemarketing \\
\hline E4 & 28 & Solteiro & Ensino Superior incompleto & Garçom \\
\hline E5 & 28 & Solteiro & Ensino Superior completo & Assessor jurídico \\
\hline E6 & 20 & Casado & Ensino Superior incompleto & Atendente de loja \\
\hline E7 & 18 & Solteiro & Ensino Médio completo & Estudante \\
\hline E8 & 23 & Solteiro & Ensino Médio Incompleto & Desempregado \\
\hline
\end{tabular}

8 Ver reportagem: "Ambulatório de Travestis e Transexuais completa 4 anos e gestores participam de evento em Brasília" (VIDERES, 2017). 
Seguindo o método proposto por Bicudo (2011), inicialmente realizamos a leitura atenta das falas após a transcrição das entrevistas; nessa leitura fomos grifando palavras-chave que faziam conexão com o objetivo do estudo. No segundo passo, fomos evidenciando os sentidos a partir do objetivo, grifando passagens que tinham relação direta com o objetivo do estudo. No terceiro passo, estabelecemos e unimos as unidades de significados a partir das palavras mais representativas e recorrentes. Por fim, estabelecemos a rede de significados expressa na figura abaixo:

Figura 1- Rede de significados

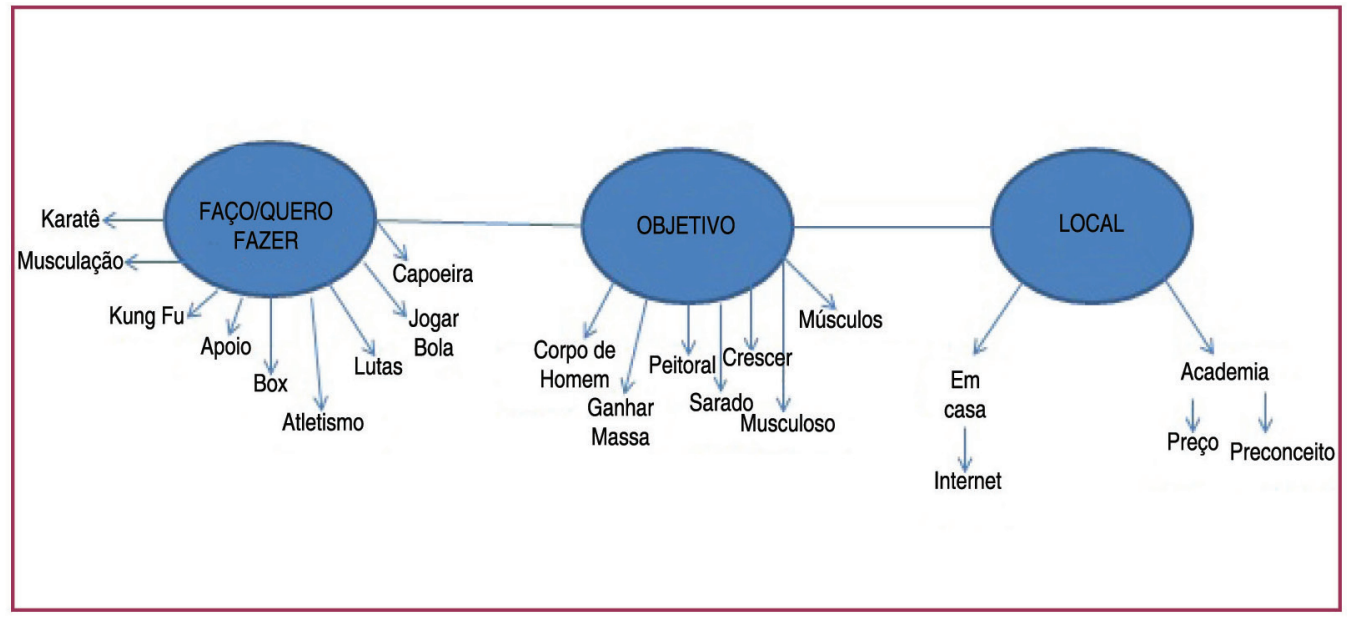

Fonte: Dados do estudo

Atualmente existem diversos recursos que auxiliam na construção/remodelação do corpo, e isso também tem relação com a identificação do gênero. Butler propõe que "[...] 0 efeito do gênero se produz pela estilização do corpo e deve ser entendido, consequentemente, como a forma corriqueira pela qual os gestos, movimentos e estilos corporais de vários tipos constituem a ilusão de um eu permanente marcado pelo gênero" (BUTLER, 2003, p. 200). Desta maneira, as pessoas trans recorrem a diversos mecanismos que possam auxiliar no processo de remodelação corporal e os homens trans buscam mecanismos que os posicionem socialmente como homens, utilizando técnicas que os masculinizem (REGO, 2014).

Não é novidade que força, vigor físico e rigidez muscular são características associadas, na sociedade ocidental, aos homens cisgênero (cujo sexo biológico e identidade de gênero são iguais). Mas, há alguns anos, devido a uma combinação de fatores políticos, sociais e culturais, foi erguida a possibilidade da participação da atividade física (com ênfase na musculação, artes marciais e lutas) na produção de tais características, e, portanto, das masculinidades de homens transgênero.

Os procedimentos estéticos e cirúrgicos alteram as formas corporais e/ou o sexo, as dietas e as terapias hormonais modificam a massa muscular e a silhueta (LE BRETON, 2013). Os exercícios físicos, além de contribuir no controle de aspectos biológicos e poder exercer influência na construção da identidade das pessoas trans, também pode funcionar como um possível instrumento para obter características físicas que podem estar relacionadas com a criação e reprodução de estereótipos criados culturalmente (SERRANO; CAMINHA; GOMES, 2017).

Os discursos dos sujeitos emergiram em torno do que eles fazem ou desejam fazer em relação as atividades físicas, o objetivo deles ao realizar ou querer realizar determinada 
atividade e o local onde essas atividades são/poderão ser realizadas. No que diz respeito às atividades que eles fazem/desejam fazer, percebemos a predominância de lutas, artes marciais e musculação.

As lutas e as artes marciais são atividades que inicialmente só eram praticadas por homens, hoje em dia esse cenário já é diferente. Todavia, há um maior número de adeptos do gênero masculino e por vezes o senso comum ainda associa essas práticas exclusivamente ao masculino. "Essas práticas de combates e contatos físicos que pressupõem força e agressividade funcionam como uma espécie de santuário sacralizado da masculinidade e virilidades tradicionais [...]" (CHAVES; ARAÚJO, 2015, p.220).

Podemos constatar isso na fala de E1, que foi proibido de realizar as atividades físicas que desejava pois sua mãe fazia associações ao masculino: "Eu tentei fazer capoeira, minha mãe não deixou porque dizia que era coisa de menino, ela me barrava em muita coisa em relação a isso, a alguma luta ou arte marcial" (E1).

Já a musculação é uma atividade física reconhecida por sua capacidade de remodelar corpos, proporcionando hipertrofia muscular aos seus praticantes. Aydian Dowling, homem trans americano, ficou em segundo lugar no concurso para capa da Men's Health. Ele conta que para alcançar o corpo de "capa de revista" fazia exercícios aeróbicos todos os dias e musculação cinco vezes por semana'. Para (REGO, 2014, p.3), "[...] o homem trans que se preocupa em tonificar os músculos vê no corpo musculoso algo que lhe ajuda performaticamente a ser visto enquanto homem, acessado através da musculação enquanto um dispositivo que produz a hipertrofia muscular". Podemos verificar isso através das falas de E2 e E3 respectivamente: "Eu não tenho vontade de ser bombadão, mas tenho vontade de ter um corpo mais definido, de homem, com uma musculatura mais visível (E2)". "O corpo musculoso é um corpo que é considerado másculo, né?!(E3)".

Nas falas acima observamos a preferência dos sujeitos por atividades associadas ao gênero/corpo masculino. Tal informação vai ao encontro da fala de Rego (2014), que escreve que os homens trans utilizam diversas técnicas corporais para transformar o corpo em direção ao masculino e distanciando do feminino, manipulando o corpo e o discurso a partir do próprio corpo. "Eles sentem-se homens, querem ser reconhecidos, em sua identidade de gênero, como homens" (SOUSA; VIANA; VALE, 2015). Assim, conclui-se que além dos objetivos físicos/ biológicos na escolha das atividades físicas, existe um processo de "masculinização" - através da produção de uma estética tida como masculina - do corpo, na tentativa de solidificar uma identidade que o transcende. Isto porque, na visão dos homens trans entrevistados, esta nova identidade masculina poderá garantir, além de satisfação com a imagem, pertencimento.

Pensando nas "preferências" dos entrevistados, cabe ressaltar que,

[...] para os homens trans, os efeitos que as modificações corporais garantem são, para além do reconhecimento, a aceitação e a proteção. Construir um corpo de homem que não porte ou expresse signos conhecidos como femininos evita uma série de violências em diversos contextos, em especial, os públicos (SOUSA; IRIART, 2018, p.5).

Assim, as mudanças nos corpos se constituem como parte do processo de formação das identidades dos homens trans, levando em consideração aspectos simbólicos dos usos sociais dos corpos (SOUSA; VIANA; VALE, 2015), mas, para além disso, também afetam 
diretamente a garantia de direitos básicos do cidadão trans, como o direito de ir e vir sem ser hostilizado.

Sobre esta questão, Bento (2012) alerta que a transexualidade está para além das amarrações entre corpo e sexo e que reproduzir um padrão binário com base nos "gêneros inteligíveis" - seja através do exercício físico ou não - pode incentivar a busca por características tipicamente masculinas como virilidade, vida profissional e sexual ativa, competitividade, etc.; porém, seguir esta lógica pode levar a sentimentos de frustração. Apesar disto, Bento (2012) admite que estando as normas de gênero também pautadas sobre algo tão maleável como 0 corpo, as modificações podem revelar a fragilidade de tais normas e gerar assim modificações nesse sistema que opera entre masculino e feminino, tornando-o igualmente flexível.

No que se refere ao objetivo dos homens trans ao realizar atividades físicas, percebemos um conjunto de palavras que pelo contexto podem ser consideradas como sinônimos, resumidas em: um corpo "de homem" musculoso. As falas de E1, E4 e E5 tratam disto quando demonstram um discurso convergente diante do questionamento sobre o corpo desejado: "Cara, eu quero ficar sarado, musculoso (E1)". "Eu quero ter um corpo mais malhado, definido (E4)". "O corpo que eu quero ter é um corpo musculoso e definido (E5)".

A busca por esse corpo "de homem" se dá por diversos motivos de ordem social e cultural. Dentro do próprio movimento de homens trans existe uma cobrança em relação a estética, como podemos perceber na fala de E3:

Eles tipo 'obrigam'. Você é um homem trans então você tem que fazer academia,
você tem que ter uma barba, você tem que ser assim e eu sou contra isso. [Esse
'eles' a quem você se refere é o coletivo de homens trans?] É. Forma o ideal
de homem trans, uma pessoa forte, musculosa, com barba, geralmente esse é o
padrão (E3).

As imagens de homens trans divulgadas na mídia são, em sua maioria, de homens fortes e musculosos, reproduzindo um padrão de corpo masculino construído socialmente, geralmente em espaços como academias de ginástica. Um exemplo disto é Tereza Brant, homem trans que divulga fotos do seu corpo - cada vez mais musculoso - transformado através da malhação e da dieta, como anuncia a matéria "Tereza Brant surpreende com corpo musculoso: acabaram as dúvidas" (TECÍDIO, 2016). Casos como esse acabam por divulgar e incentivar um modelo estético de referência para os homens trans, que tem relação com a necessidade de pertencimento. Isto ocorre pela "[...] preocupação de modificar o olhar sobre si e o olhar dos outros a fim de sentir-se existir plenamente" (LE BRETON, 2013, p. 30). Esta afirmação remete à necessidade do homem - e da mulher trans - de alinhar da forma que considere ideal para si três fatores: a interpretação própria da construção social de gênero; a sua (auto)percepção de gênero, ou seja, o que é considerado como viável para si; aquilo que ele(a) deseja comunicar sobre gênero através do seu corpo, em matéria de símbolos e técnicas corporais.

Analisando os locais em que os sujeitos já realizaram ou querem realizar atividades físicas, dois deles têm protagonismo nas falas: a casa e a academia. As academias despontam como um espaço que oferece grande diversidade de atividades e exercícios físicos. Nesse sentido, a academia seria um espaço viável, todavia, dois motivos levam os entrevistados a realizarem atividades físicas em casa: o preconceito e a falta de recursos financeiros. Em relação ao preconceito, E3 diz que foi tratado na academia como mulher. Comentou que isso 
o incomodou e gostaria de não precisar passar por tudo isso novamente. Já E4 diz temer não encontrar uma academia que o respeite e que por problemas financeiros se exercita em casa. Quando eles "optam" por se exercitar em casa, surge o recurso da internet como guia para esses exercícios, seja através de pesquisas avulsas, seja através de relatos de experiências de outros homens trans, como afirma E4 e E6 respectivamente:

Eu procurava na internet, cada dia eu fazia um treino para um músculo diferente. Em seguida, fazia uma pausa naquele músculo e assim cada vez eu ia mudando as séries (E4).

[Quais os exercícios que você faz em casa?] Abdominal e apoio. [Por quê?] Por que alguns homens trans disseram que esse tipo de exercício ajuda a diminuir 0 peitoral, que é o que eu tenho mais interesse (E6).

A vontade de modificar o corpo por meio da atividade física faz com que esses sujeitos superem os desafios impostos e encontrem maneiras alternativas de continuar o processo na busca de construir um corpo musculoso que se configure como homens trans. Além disso, a produção de significados não se reduz aos resultados, mas também ao processo, se fazer presente nesses ambientes, compartilhando de práticas masculinas, colabora para o sentimento de pertencimento (REGO, 2014). Sendo assim, acredita-se neste estudo que as atividades físicas surgem como uma possibilidade para os homens trans no processo de (re) construção do próprio corpo por terem a capacidade de remodelar os corpos a partir de uma prática sistematizada para um objetivo, podendo tornar o corpo mais magro, mais musculoso, mais definido, de acordo com o objetivo de quem o pratica.

Como lembra Louro (1997, p.75) "[...] não se pode negar que ser o melhor, no esporte, pode representar especialmente para um menino ou um jovem, um valorizado símbolo de masculinidade". Nesse sentido, a prática da atividade física se constitui efetivamente como forma de significar e ressignificar o processo de autoidentificação dos homens trans.

\section{CONCLUSÃO}

Estudando as relações de gênero tendo como pano de fundo os avanços tecnocientíficos e o desenvolvimento da Biomedicina, é possível perceber que desde a segunda metade do século XX são colocados em questão aspectos - como a masculinidade do homem trans que pareciam antes inatingíveis. A masculinidade é um objeto de produção permanente por um uso apropriado dos símbolos, de uma redefinição de si conforme o design corporal (LE BRETON, 2013). Nessa busca, os homens trans recorrem às atividades físicas, como lutas e musculação, na certeza de que essas técnicas podem remodelar seus corpos, proporcionando uma musculatura hipertrofiada que serve como moeda de troca no mercado simbólico do binarismo sexual masculino-feminino e que levará teoricamente à aceitação social (REGO, 2014). Sobre esta questão, sugere-se a discussão futura de aspectos relacionados à transfobia, principalmente no âmbito do esporte e do exercício físico.

As atividades físicas estão presentes em todas as camadas sociais no dia a dia de diferentes sujeitos por diversos motivos diferentes. A musculação, bem como outras atividades físicas, pode alterar aquilo que não os satisfaz, além de inseri-los em um contexto masculino, já que é "[...] buscada a força muscular em si, em sua dimensão simbólica de restauração de identidade" (LE BRETON, 2013, p. 43). 
Diversos objetivos são enumerados para justificar a busca por essas atividades, entretanto, todos circulam no mesmo eixo, obter um corpo "de homem" que os faça ser reconhecidos no masculino. Nesse contexto, a "musculação pode ser vista como uma cirurgia simbólica, ela tem uma eficácia discursiva que é produzida pelo manejo do corpo" (REGO, 2015, p.8). Isto quer dizer que ela funciona como um provável instrumento de modificação dos corpos e das identidades masculinas. Mas não só a musculação desempenha esse papel, as atividades físicas e o exercício físico também podem ser considerados recursos que proporcionam ao sujeito construir seu corpo de acordo com seu desejo, o que leva à conclusão de que o corpo está intimamente ligado à construção da identidade de gênero. No entanto, cabe enfatizar que cada sujeito tem uma forma própria de lidar com o gênero e com a sua performance no espaço público. Ademais, isto também não quer dizer que a possibilidade de 0 sujeito ter encontrado recursos na Biomedicina e tecnociência de produzir o próprio corpo iniba o caráter relacional das identidades sexuais, uma vez que na construção do corpo do homem trans há muito da construção social da masculinidade ocidental e cisgênero.

Este estudo concluiu que os entrevistados fazem uso das atividades físicas em busca do ganho de massa corporal e definição muscular, aspectos que na visão dos entrevistados remetem a um corpo masculino, reforçando não apenas a sua masculinidade, mas ajudando na construção da sua identidade sexual. Acredita-se nesta pesquisa que o ideal de corpo masculino dos homens trans esteja diretamente ligado a referências fornecidas pela mídia e/ou baseado em uma construção social de masculino. Pois, assim como qualquer outro segmento social, os homens trans possuem interesses e motivações construídos ao longo da sua trajetória de vida, e, portanto, são influenciados pelo contexto social, histórico e cultural ao qual pertencem.

Um fato importante a se destacar é a necessidade de se combater a transfobia também dentro dos espaços destinados às práticas de atividade física, sejam eles públicos ou privados, a fim de oferecer ambientes de qualidade para a prática dessas atividades a toda população, evitando que esses sujeitos se exponham a realizar atividade sem orientação especializada correndo o risco de sofrer lesões ou de não alcançar o objetivo predeterminado. A pesquisa aqui apresentada se deteve a analisar a relação dos homens trans com as atividades físicas no processo de mudanças corporais, todavia, a ênfase foi dada aos discursos fora do ambiente em que eles realizam essas práticas, de modo que sugerimos a realização de outros estudos dentro desses ambientes para que sejam observados outros fatores que possam vir a contribuir com o resultado da pesquisa.

\section{REFERÊNCIAS}

ALMEIDA, Guilherme. "Homens Trans": Novos Matizes na Aquarela das Masculinidades? Estudos Feministas, v. 20, n. 2, p. 513-523, maio/ago. 2012.

ÁVILA, Simone; GROSSI, Miriam Pillar. "Maria, Maria João, João: reflexões sobre a transexperiência masculina". In: FAZENDO GÊNERO, 9, 2010 diásporas, diversidade, deslocamentos, 2010, Florianópolis. Anais [...]. Florianópolis: 2010. Disponível em: http://www.fazendogenero.ufsc.br/9/ resources/anais/1278255349 ARQUIVO Maria,MariaJoao,Joa0040721010.pdf. Acesso em: 11 fev. 2018. 
BENTO, Berenice. A reinvenção do corpo: sexualidade e gênero na experiência transexual. 2. ed. Natal: EDUFRN, 2014a.

BENTO, Berenice. O que pode uma teoria? Estudos transviados e a despatologização das identidades trans. Florestan, v.1, n.2, p. 46-66, nov. 2014b.

BENTO, Berenice. Sexualidade e experiências trans: do hospital à alcova. Ciência Saúde Coletiva, v. 17, n. 10, p. 2655-2664, out. 2012. Disponível em: http://www.scielo.br/scielo.php?script=sci_arttext\&pid=S1413-81232012001000015\&lng=en\&nrm=iso. Acesso em: 02 out. 2016.

BICUDO, Maria Aparecida Viggiani. Pesquisa qualitativa e pesquisa qualitativa segundo a abordagem fenomenológica. São Paulo: Cortez, 2011.

BUTLER, Judith. Problemas de gênero: Feminismo e subversão de identidade. Rio de Janeiro: Civilização Brasileira, 2003.

CARVALHO, Yara Maria. Promoção da saúde, Práticas Corporais e Atenção Básica. Revista Brasileira Saúde da Família, p. 33-45, 2006. Disponível em: http://bvsms.saude.gov.br/bvs/ periodicos/saudefamilia/revista saude familia11.pdf. Acesso em: 11 fev. 2019.

CHAVES, Paula Nunes; ARAÚJO, Allyson Carvalho de. Pensando o corpo travestido e transexualizado no esporte: uma análise da película Beautiful Boxer. Motrivivência, v.27, n. 45, p. 219-229, set. 2015.

GASKELL, George; BAUER, Martin W. Pesquisa qualitativa com texto, imagem e som: um manual prático. Petrópolis: Vozes, 2012.

GHIROTTO, Edoardo. Atletismo tem regras mais rígidas do que o $\mathrm{COI}$ para atletas transgênero. Folha de S. Paulo, abr. 2018. Disponível em: https://www1.folha.uol.com.br/esporte/2018/04/atletismo-tem-regras-mais-rigidas-do-que-o-coi-para-atletas-transgenero.shtml. Acesso em: 12 de nov. 2017.

GRESPAN, Carla Lisboa; GOELLNER, Silvana Vilodre. Fallon Fox: um corpo queer no octógono. Movimento, v.20, n.4, p. 1265-1282, out./dez. 2014.

LE BRETON, David. Adeus ao Corpo. 6. ed. São Paulo: Papirus, 2013.

LIMA, Fátima. Biotecnologias, modos de subjetivação e práticas de si nos processos de hormonização entre homens transexuais. In: REUNIÃO BRASILEIRA DE ANTROPOLOGIA, 29. 2014, Natal. Anais [...]. Natal: 2014. Disponível em: <http://www.29rba.abant.org.br/resources/anais/1/1401371223 ARQUIVO Biotecnologias, modosdesubjetivacaoepraticasdesinosprocessosdehormonizacaoentrehomenstransexuais.pdf>. Acesso em: 25 mar. 2018.

LIMA, Samantha. O papel do SUS em ajudar cidadãos transexuais a renascer. Revista Época, jun. 2017. Disponível em: https://epoca.globo.com/saude/noticia/2017/06/o-papel-do-sus-em-ajudar-cidadaos-transexuais-renascer.html. Acesso em: 11 nov. 2017.

LOURO, Guacira. Gênero, sexualidade e educação: uma perspectiva pós-estruturalista. Petrópolis: Vozes, 1997.

MALYSSE, Stéphane. Em busca dos (H)alteres-ego: olhares franceses nos bastidores da corpolatria carioca. In: GOLDENBERG, Miriam. (org.). Nu \& vestido: dez antropólogos revelam a cultura do corpo carioca. 2. ed. Rio de Janeiro: Record, 2002.p. 79- 137.

PITANGA, Francisco José Gondim. Epidemiologia, atividade física e saúde. Revista Brasileira de Ciência e Movimento, v.10, n. 3, p.49-54, jul. 2002.

REGO, Francisco Cleiton Vieira Silva. Hipertrofia muscular como expressão da masculinidade entre homens transexuais: Masculinidade e ética antropológica. In: REUNIÃO BRASILEIRA DE ANTROPOLOGIA, 29, 2014, Natal. Anais .... Natal: 2014. Disponível em: http://www.29rba.abant.org. br/resources/anais/1/1401924790 ARQUIVO REGO,FCVS GT24 HIPERTROFIAMUSCULAR.pdf. Acesso em: 25 mar. 2018. 
REGO, Francisco Cleiton Vieira Silva. Hipertrofia muscular como Tecnologia de Gênero na produção de masculinidades entre Homens Transexuais. In: ENCONTRO ANUAL DA ANPOCS, 38, 2015.

Caxambu. Anais ... Caxambu: 2015. Disponível em: https://anpocs.com/index.php/encontros/papers/ 38-encontro-anual-da-anpocs/gt-1/gt33-1/9144-sexualidade-e-genero-sujeitos-praticas-regulacoes/file. Acesso em: 25 mar. 2018.

ROCON, Pablo Cardozo et al. O que esperam pessoas trans do Sistema Único de Saúde? Interface (Botucatu), v. 22, n. 64, p. 43-53, mar. 2018. Disponível em: http://www.scielo.br/scielo.php?script=sci arttext\&pid=S1414-32832018000100043\&lng=en\&nrm=iso. Acesso em: 26 mar. 2018.

ROSSET, Tatiane. Esta garota está prestes a se tornar o primeiro homem transgênero a estrelar capa da 'Men's Health'. Veja São Paulo, fev. 2017. Disponível em: https://vejasp.abril.com.br/blog/pop/esta-garota-esta-prestes-a-se-tornar-o-primeiro-homem-transgenero-a-estrelar-capa-da-8216-men-8217-s-health-8217/. Acesso em: 11 nov. 2017.

SANCHO GIL, Juana Maria. Inovação e investigação educativa: aproximação de uma relação incerta. In: MOLINA NETO, Vicente; TRIVIÑOS. Augusto Nibaldo Silva. Pesquisa qualitativa na Educação Física: Alternativas Metodológicas. 3. ed. Porto Alegre: Sulina, 2010.

SERRANO, Jéssica Leite; CAMINHA, Iraquitan de Oliveira; GOMES, Isabelle Sena. Transexualidade e Educação Física: uma revisão sistemática em periódicos das Ciências da Saúde. Movimento, v.23, n.3, p.1119-1132, jul./set. 2017. Disponível em: https://seer.ufrgs.br/Movimento/article/ viewFile/64857/43889. Acesso em: 2 maio de 2018.

SOUSA, Diogo; IRIART, Jorge. "Viver dignamente": necessidades e demandas de saúde de homens trans em Salvador, Bahia, Brasil. Cad. Saúde Pública, Rio de Janeiro, v. 34, n. 10, e00036318, 2018. Disponível em: http://www.scielo.br/scielo.php?script=sci arttext \&pi$\mathrm{d}=S 0102-311 X 2018001005007 \&$ lng=pt\&nrm=iso. Acesso em: 16 fev. 2019.

SOUSA, Eduardo Sergio; VIANA, Alba Jean Batista; VALE, Johnatan Marques. Os homens trans e a corporeidade: o complexo fenômeno da busca do sujeito social masculino. In: BRASIL. Ministério da Saúde. Transexualidade e Travestilidade na Saúde. Brasília, 2015. p. 11-127.

TAHARA, Alexander Klein; SCHWARTZ, Gisele Maria; SILVA, Karina Acerra. Aderência e manutenção da prática de exercícios em academias. Revista Brasileira de Ciência e Movimento, v.11, n.4, p. 7-12, out./dez. 2003.

TECÍDEO, Luciana. Tereza Brant surpreende com corpo musculoso: 'Acabaram as dúvidas'. EGO, jun. 2016. Disponível em: http://ego.globo.com/famosos/noticia/2016/06/tereza-brant-surpreende-com-corpo-musculoso-acabaram-duvidas.html. Acesso em: 11 nov. 2017.

VIDERES, Thaysa. Ambulatório de Travestis e Transexuais completa 4 anos e gestores participam de evento em Brasília. Blog pauta PB, jun. 2017. Disponível em: http://pautapb.com.br/2017/07/20/ ambulatorio-de-travestis-e-transexuais-completa-4-anos-e-gestores-participam-de-evento-em-brasilia/. Acesso em: 11 nov. 2017.

Apoio:

O presente trabalho foi realizado com apoio da Coordenação de Aperfeiçoamento de Pessoal de Nível Superior - Brasil (CAPES) - Código de Financiamento 001. "This study was financed in part by the Coordenação de Aperfeiçoamento de Pessoal de Nível Superior - Brasil (CAPES) - Finance Code 001”. 